\title{
The inclusion complex of rosmarinic acid into beta-cyclodextrin: A thermodynamic and structural analysis by NMR and capillary electrophoresis
}

\author{
Amra Aksamija ${ }^{\mathrm{a}}$, Ange Polidori ${ }^{\mathrm{b}}$, Raphaël Plasson ${ }^{\mathrm{a}}$, Olivier Dangles ${ }^{\mathrm{a}}$, Valérie Tomao ${ }^{\mathrm{a}, *}$ \\ a University of Avignon, INRA, UMR408 SQPOV, 84000 Avignon, France \\ ${ }^{\mathrm{b}}$ University of Avignon, UMR5247 CBSA, 84000 Avignon, France
}

\begin{abstract}
A B S T R A C T
This work focuses on the characterization of the rosmarinic acid (RA)- $\beta$-cyclodextrin (CD) complex in aqueous solution by ${ }^{1} \mathrm{H}$ NMR (1D- and 2D-ROESY), completed with studies by capillary electrophoresis (CE). From the ${ }^{1} \mathrm{H}$ NMR data, the stoichiometry of the complex was determined by a Job's plot and the binding constant was estimated from a linear regression (Scott's method). At $\mathrm{pH} 2.9$, the results showed that RA binds CD with a $1: 1$ stoichiometry and a binding constant $K_{b}$ of $445( \pm 53) \mathrm{M}^{-1}$ or $465( \pm 81) \mathrm{M}^{-1}$ depending on the $\mathrm{CD}$ protons ( $\mathrm{H}-5$ or $\mathrm{H}-3$ ) selected for the evaluation. The $K_{b}$ value was also calculated from the $\mathrm{CD}$-induced chemical shifts of each RA proton in order to collect information on the structure of the complex.

The $\mathrm{pH}$ dependence of $K_{b}$ revealed that the RA carboxylic form displays the highest affinity for $\mathrm{CD}$. An investigation by capillary electrophoresis fully confirmed these results. 2D ROESY analysis provided detailed structural information on the complex and showed a strong correlation between $\mathrm{H}-3$ and $\mathrm{H}-5$ of $C D$ and most RA protons. In conclusion, RA, an efficient phenolic antioxidant from rosemary with a marketing authorization, spontaneously forms a relatively stable inclusion complex with $\mathrm{CD}$ in water.
\end{abstract}

\section{Introduction}

Naturally occurring phenolic compounds are currently used in the food industry as additives, especially in functional foods due to their potential health promotion in terms of antioxidant and anti-inflammatory protection (Campos-Vega, Guadalupe LoarcaPiña, \& Oomah, 2010).

Rosmarinic acid (RA), an ester of caffeic acid and 3,4-dihydroxyphenyllactic acid, is a natural phenolic compound commonly found in many Lamiaceae herbs such as Rosmarinus officinalis, an aromatic evergreen shrub. Besides its antioxidant and anti-inflammatory activities, RA has antiallergenic, antiviral, and antibacterial properties and displays a very low toxicity (Petersen \& Simmonds, 2003) and (Furtado, de Almeida, Furtado, Cunha, \& Tavares, 2008). To fulfill the consumer demand for natural food additives, rosemary extracts have been recently accepted by the EU food additive legislation as effective and natural alternatives to synthetic antioxidants.

\footnotetext{
* Corresponding author.

E-mail address: valerie.tomao@univ-avignon.fr (V. Tomao).
}

However, the effectiveness of these natural antioxidants depends on the preservation or improvement of their stability, bioactivity and bioavailability (Fang \& Bhandari, 2010). Nanoencapsulation within food-grade macromolecules represents a remarkable mean to maintain the structural integrity and potentially enhance the bioavailability of these bioactive compounds (Munin \& Edwards-Lévy, 2011). Cyclodextrins, a group of naturally occurring macrocyclic oligosaccharides, are convenient encapsulating material widely used in the food industry as additives for the stabilization of flavors and for the elimination of undesired tastes (Astray, Gonzalez-Barreiro, Mejuto, Rial-Otero, \& SimalGándara, 2009). In particular, $\beta$-cyclodextrin (CD) has been listed as a safe food additive since 1998 (Szente \& Szejtli, 2004). Inclusion of natural phenols into $C D$ enables their protection against enzymatic oxidation and non-enzymatic oxidation by dioxygen and thus can extend their stability over time (Cravotto, Binello, Baranelli, Carraro, \& Trotta, 2006).

Numerous analytical methods, such as spectroscopic, electrochemical or separation techniques, have been used for the characterization of the inclusion complexes and the estimation of the thermodynamic parameters of binding (Mura, (2014)). Among 
Version définitive du manuscrit publiée dans / Final version of the manuscript published in :

Food Chemistry (2016), Vol. 208, p. 258-263, DOI: 10.1016/j.foodchem.2016.04.008

Journal homepage : www.elsevier.com/lor.te/foodchem

these methods, ${ }^{1} \mathrm{H}$ NMR is the most widely used (Pessine, Calderini, \& Alexandrino G.L., 2012).

In aqueous solution, CDs are able to form inclusion complexes with a variety of phenolic compounds such as hydroxytyrosol (López-García, López, Maya, \& Fernández-Bolaños, 2010), baicalin (Li, Zhang, Chao, \& Shuang, 2009), isoquercitrin (Wang et al., 2009), quercetin (Koontz, Marcy, O'Keefe, \& Duncan, 2009), and caffeic acid (Zhang, Li, Zhang, \& Chao, 2009). This ability is due to their cone-shaped structure with a relatively lipophilic inner cavity and hydrophilic outer surface. The main driving force in complex formation is the release of high-enthalpy water molecules from the CD cavity and the development of strong van der Waals host (CD) - guest (ligand) interactions (Loftsson, Jarho, Másson, \& Järvinen, 2005). Water molecules are displaced by the more hydrophobic guest molecules with a concomitant decrease of CD ring strain (Szejtli, 1998).

However, only few papers have been published on the inclusion of RA into CDs. Celik et al. have studied the CD-RA binding and the corresponding changes in antioxidant capacity of RA in solution using UV-visible and fluorescence spectroscopies (Çelik, Özyürek, Tufan, Güçlü, \& Apak, 2011). Recently, Medronho et al. reported for the first time an NMR study of the $\beta$-CD-RA interactions, giving insight on the complex structure (Medronho, Valente, Costa, \& Romano, 2014); however, much higher values (by one order of magnitude) of the association constant were estimated in this work.

These conflicting results prompted us to revisit CD-RA binding. As RA could be encapsulated in CD for application in foods of variable acidity, we also investigated the $\mathrm{pH}$-dependence of the CD-RA binding to compare the affinity of the carboxylic and carboxylate

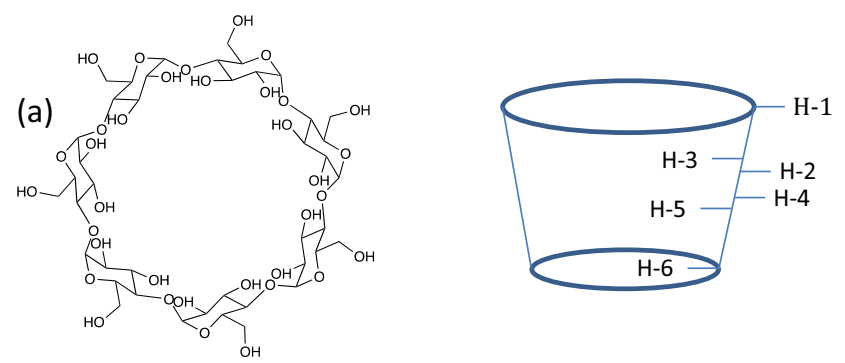

(b)

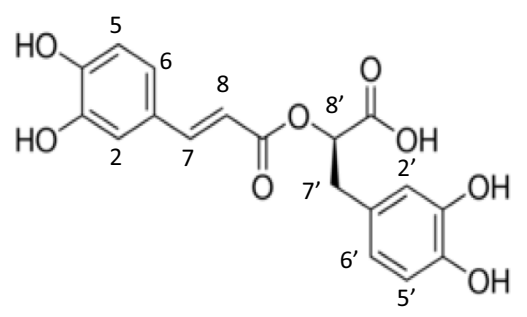

(c)

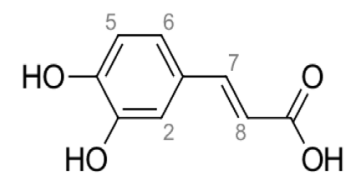

Fig. 1. Chemical structures of (a) $\beta$-cyclodextrin (CD), (b) rosmarinic acid (RA), (c) caffeic acid (CA). forms of RA for the macrocycle. In this work, the CD-RA inclusion complex (Fig. 1) was investigated by 1D and 2D (ROESY) ${ }^{1} \mathrm{H}$ NMR in order to refine the structural characterization of the complex. Additionally, a complementary study by CE was performed. The values of the binding constant $\left(K_{\mathrm{b}}\right)$ obtained by independent analytical tools (fluorescence spectroscopy, NMR and CE) in different studies (Çelik, 2011; Medronho et al., 2014 and this work) will be discussed.

The experimental conditions for the formation of the inclusion complex are consistent with the EU food additive legislation.

\section{Materials and methods}

\subsection{Materials}

Rosmarinic acid, caffeic acid (CA), sodium dihydrogenphosphate dihydrate and disodium hydrogenphosphate heptahydrate were purchased from Sigma Aldrich (St. Louis, MO, USA). $\beta$-Cyclodextrin was kindly given by Roquette Freres (Lestrem, France). Sodium hydroxide was purchased from Prolabo (BDH Prolabo, VWR International, Haasrode, Belgium). Phenol was obtained from Carlo Erba (Carlo Erba Reagents, SdS, Peypin, France). $\mathrm{D}_{2} \mathrm{O}$ for NMR analyses was purchased from Euriso-Top (Saint-Aubin, France). Demineralized water was obtained from VWR (VWR International S.A.S, France). Standard solutions for capillary conditioning, $0.1 \mathrm{M}$ and $1.0 \mathrm{M} \mathrm{NaOH}$ solutions were supplied by Fluka Biochemika (Sigma-Aldrich Chemie, GmbH, Steinheim, Germany) while milliQ water was produced by an EASY pure RF compact ultrapure water system (Barnstead, ThermoFicher Scientific, Waltham, MA, USA). All reagents were of analytical grade quality.

\subsection{NMR study}

All RA and CD solutions were freshly prepared in $\mathrm{D}_{2} \mathrm{O}$. For the Job's plot, different volumes of $10 \mathrm{mM}$ solutions of RA and CD in $\mathrm{D}_{2} \mathrm{O}$ were mixed together to a constant volume keeping the sum of the total RA and CD concentrations equal to $10 \mathrm{mM}$.

For the determination of the apparent association constant (Scott's plot), two different series of samples were prepared.

In the first one, different volumes of a $1 \mathrm{mM} C D$ solution in $\mathrm{D}_{2} \mathrm{O}$ and of a solution containing RA $(10 \mathrm{mM})$ and $\mathrm{CD}(1 \mathrm{mM})$ in $\mathrm{D}_{2} \mathrm{O}$ were mixed together to a constant volume with a final $\mathrm{RA} / \mathrm{CD}$ ratio ranging from 0.8 to 9.2 .

In the second series, different volumes of a $1 \mathrm{mM}$ RA solution and of a solution containing $C D(10 \mathrm{mM})$ and $\mathrm{RA}(1 \mathrm{mM})$ in $\mathrm{D}_{2} \mathrm{O}$ were mixed together to a constant volume with a final $\mathrm{CD} / \mathrm{RA}$ ratio ranging from 0.8 to 9.2. Final solutions were equilibrated at room temperature and protected from light before measurement.

1D ${ }^{1} \mathrm{H}$ NMR spectra were recorded on a Bruker AC- $400 \mathrm{MHz}$ spectrometer (software Bruker Top Spin 2.1). 2D-ROESY spectra were recorded in on a Bruker AVL $600 \mathrm{MHz}$ (Spectropole, AixMarseille University).

Chemical shifts are given in ppm $(\delta)$ and calculated using the internal reference of the HDO signal at $4.79 \mathrm{ppm}$. In all cases, the complexation-induced chemical shift difference is defined as the difference between the chemical shift of the free molecule to the chemical shift of bound molecule, $\Delta \delta=\delta_{\text {free }}-\delta_{\text {complex}}$.

\subsection{Capillary Electrophoresis study}

Electrophoresis experiments were performed using an automated capillary electrophoresis system (Beckman P/ACE MDQ, Fullerton, CA). Fused-silica capillaries $(50 \mu \mathrm{m}$ i.d. $\times 60 \mathrm{~cm}, 50 \mathrm{~cm}$ to the detector) were used. 
Phosphate buffer ( $\mathrm{pH}$ 7) for CE analysis was prepared with sodium dihydrogenphosphate dihydrate and disodium hydrogenphosphate heptahydrate in milliQ water (ionic strength $=10 \mathrm{mM}$ ) and stored at $4{ }^{\circ} \mathrm{C}$. Working buffers were prepared by diluting up to $15 \mathrm{mM}$ of $\mathrm{CD}$ in this phosphate buffer.

Stock solutions of RA and CA, both in final concentration equal to $5 \mathrm{mM}$, were prepared in milliQ water and protected from light at $4{ }^{\circ} \mathrm{C}$. Sodium thiosulphate $(1 \mathrm{mM})$ was added to protect the stock solutions against oxidation. Sonication of the stock solutions in an ultrasonic bath ( $5 \mathrm{~min}$ ) was necessary to achieve complete solubility. The stock RA and CA solutions were renewed every 15 days. Samples for analysis were prepared by dilution of these stock solutions in milliQ water. After dilution, the concentrations were $0.05 \mathrm{mM}$ for RA, $0.2 \mathrm{mM}$ for CA and $1 \mathrm{mM}$ for phenol.

Prior to first use, new capillaries were conditioned by flushing at 20 psi with milliQ water ( $2 \mathrm{~min}), 0.1 \mathrm{M} \mathrm{NaOH}(10 \mathrm{~min}), 1.0 \mathrm{M}$ $\mathrm{NaOH}$ ( 5 min), milliQ water ( 2 min), then with working buffer for $15 \mathrm{~min}$. In order to remove potentially adsorbed analytes, the capillary was rinsed with milliQ water ( $2 \mathrm{~min}), 0.1 \mathrm{M} \mathrm{NaOH}(5 \mathrm{~min})$, milliQ water ( $2 \mathrm{~min}$ ) and working buffer ( $5 \mathrm{~min}$ ) every three consecutive runs. Before each sample run, the capillary was flushed with $0.1 \mathrm{M} \mathrm{NaOH}(1 \mathrm{~min})$ and working buffer $(5 \mathrm{~min})$ and, after analysis, with working buffer $(2 \mathrm{~min})$. The capillary was thermostated at $20^{\circ} \mathrm{C}$. The sample was injected in hydrodynamic mode at 0.5 psi for $5 \mathrm{~s}$ and each analysis was performed under an applied voltage of $10 \mathrm{kV}$. Any measurement was repeated at least three times in identical conditions.

\section{Results and discussion}

\subsection{Stoichiometry of the inclusion complex}

The stoichiometry of inclusion complex between RA and CD was determined by using the method of continuous variations (Job's plot).

The CD protons that are most sensitive to bound RA are H-3 and $\mathrm{H}-5$, as both points toward the interior of the cavity. The significant diamagnetic shift observed for those protons is essentially due to the magnetic anisotropy effects of RA's $\pi$-electrons in agreement with the formation of an inclusion complex (Ali \& Upadhyay, 2008; Schneider, Hacket, \& Rudiger, 1998). Table S1 shows the chemical shifts differences of $\mathrm{H}-5(\mathrm{CD})$ for a $\mathrm{CD}$ mole fraction $\left(r_{\mathrm{CD}}\right)$ ranging from 0.1 to 0.9 . It is also noteworthy that the aromatic protons $\mathrm{H}-2, \mathrm{H}-6, \mathrm{H}^{\prime}$ ' and $\mathrm{H}-\mathrm{6}^{\prime}$ of RA are also diamagnetically shifted. By contrast the other $\mathrm{CD}$ protons ( $\mathrm{H}-1, \mathrm{H}-2, \mathrm{H}-4$ and $\mathrm{H}-6)$, mostly localized outside the $C D$ cavity, experience insignificant chemical shift variations. The superposition of the NMR spectra shows a significant shielding of the internal protons $\mathrm{H}-3$ and $\mathrm{H}-5$ of $\mathrm{CD}$ (Fig. 2). The stoichiometry of the inclusion complex was determined by plotting $r_{\mathrm{CD}} \times \Delta \delta(\mathrm{H}-3, \mathrm{CD})$ against $r_{\mathrm{CD}}$ by using the Job's method (Fig. S1). The symmetry of the curve obtained and its maximum at $r_{\mathrm{CD}}=0.5$ both point to a single complex of $1: 1$ stoichiometry. The same conclusion was reached with $\mathrm{H}-5$. These results are in agreement with previous investigations by fluorescence spectroscopy ( $C$, elik, 2011) and NMR (Medronho et al., 2014).

\subsection{Stability of the inclusion complex}

The apparent binding constant $K_{b}$ was calculated according to the conventional Scott's equation assuming 1:1 binding.

$\frac{[R A]}{\Delta \delta_{o b s}}=\frac{[R A]}{\Delta \delta_{\max }}+\frac{1}{K_{b} \Delta \delta_{\max }}$

$\Delta \delta_{\text {obs }}$ represents the observed chemical shift difference of CD proton $\mathrm{H}-3$ or $\mathrm{H}-5$ between free $\mathrm{CD}$ and the $\mathrm{CD}+\mathrm{RA}$ mixtures.

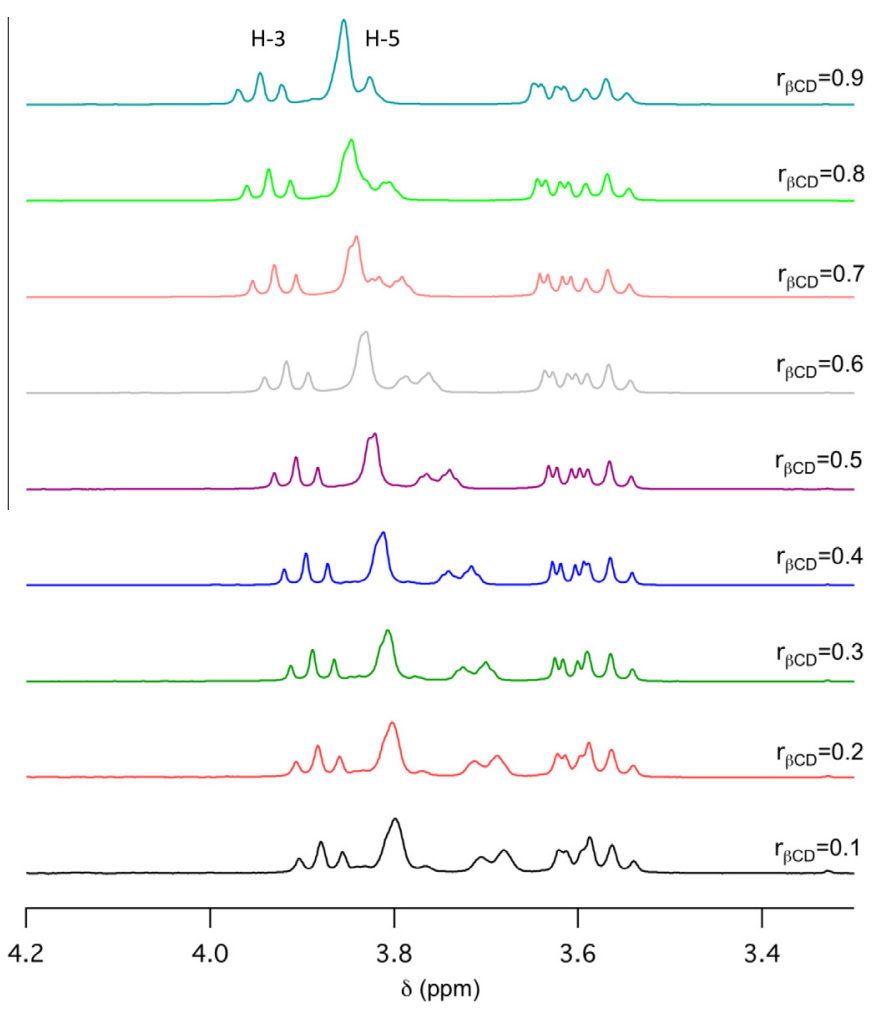

Fig. 2. Expansion of the ${ }^{1} \mathrm{H}$ NMR spectrum showing the displacement of $\mathrm{H}-5$ and $\mathrm{H}-$ $3(\mathrm{CD})$ for a $\mathrm{CD}$ mole fraction $(r C D)$ ranging from 0.1 to 0.9 in $\mathrm{D}_{2} \mathrm{O}$ at $\mathrm{pH} 2.9$. Different volumes of $10 \mathrm{mM}$ solutions of $\mathrm{RA}$ and $\mathrm{CD}$ were mixed together to a constant volume keeping the sum of the total RA and CD concentrations equal to $10 \mathrm{mM}$ in $\mathrm{D}_{2} \mathrm{O}$ at $\mathrm{pH} 2.9$.

$\Delta \delta_{\max }$ is the chemical shift difference at saturation. The $[\mathrm{RA}] / \Delta \delta_{\text {obs }}$ ratio for $\mathrm{H}-5$ was plotted as a function of [RA], thus resulting in an excellent linear fit (Fig. 3). This confirms the 1:1 stoichiometry of the inclusion complex in agreement with the Job's plot. From the slope of the plot, one obtains: $\Delta \delta_{\max }=0.22 \pm 0.01 \mathrm{ppm}$. The same plot with $\mathrm{H}-3$ yields: $\Delta \delta_{\max }=0.10 \pm 0.01 \mathrm{pm}$. The slope-tointercept ratio equals the binding constant. From the $\mathrm{H}-5$ and $\mathrm{H}-3$ plots respectively, one obtains: $K_{b}=445 \pm 53 \mathrm{M}^{-1}$ and $465 \pm 81 \mathrm{M}^{-1}$. As expected, both values are identical within experimental error.

RA displays two phenolic rings and each of them may be involved in the binding. A second series of measurements, in which $\mathrm{RA}$ is in low and constant concentration $(1 \mathrm{mM})$ and $\mathrm{CD}$ in variable

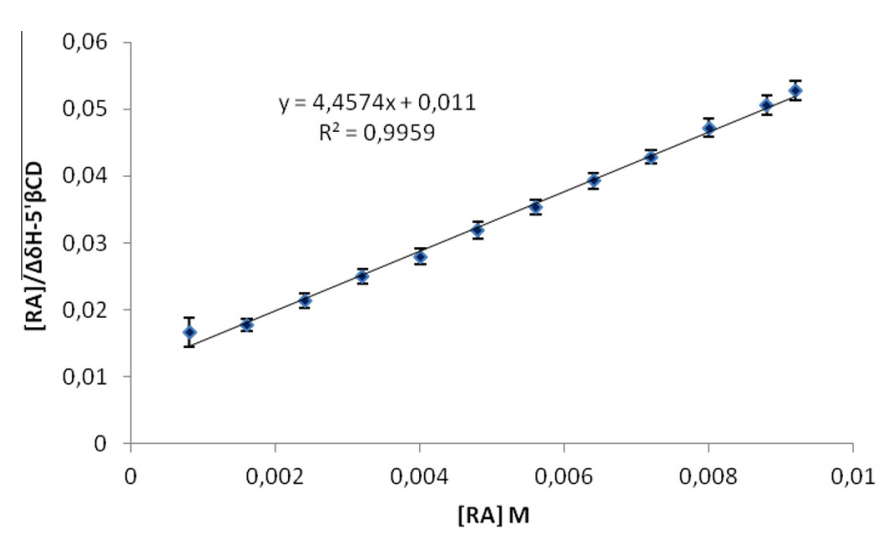

Fig. 3. Scott's plot for $C D$ proton $H-5$ with $C D$ concentration set at $1 \mathrm{mM}$ and variable $\mathrm{RA}$ concentration in $\mathrm{D}_{2} \mathrm{O}$ at $\mathrm{pH} 2.9$. 
Version définitive du manuscrit publiée dans / Final version of the manuscript published in :

Food Chemistry (2016), Vol. 208, p. 258-263, DOI: 10.1016/j.foodchem.2016.04.008

Journal homepage : www.elsevier.com/lor.te/foodchem

concentration, was performed to collect information on the structure of the complex. Although the CD-induced chemical shift displacements of the RA protons are weak, Scott's plots could be constructed to estimate $\Delta \delta_{c}$ and $K_{b}$. The $K_{b}$ values thus obtained are slight lower than the one obtained by monitoring the $\mathrm{CD}$ protons (Table S2). The latter are considered more reliable based on the higher sensitivity of the CD protons (especially H-5) to RA-CD binding, which is obvious from the larger $\Delta \delta_{\max }$ values.

\subsection{Structure of the inclusion complex}

The assignments of RA protons were made on the basis of their specific coupling constants and on the COSY spectrum. The complete ${ }^{1} \mathrm{H}$ NMR data for each of RA protons is presented in the Table S3 and is consistent with those previously obtained in the literature (Lecomte, Giraldo López, Laguerre, Baréa, \& Villeneuve, 2010). Analysis of the NMR spectrum of RA ( $1 \mathrm{mM})$ shows signals of six aromatic protons (H-2, H-5, H-6 and H-2', H-5', H-6'), two vinylic protons $(\mathrm{H}-7, \mathrm{H}-8)$ and three aliphatic protons $\left(\mathrm{H}^{\prime}{ }_{\mathrm{a}}, \mathrm{H}^{\prime}{ }_{\mathrm{b}}\right.$ and $\mathrm{H}-8^{\prime}$ ).

In Fig. $\mathrm{S} 2$, the ${ }^{1} \mathrm{H}$ NMR data show the large variations induced by RA on the chemical shifts of the CD protons located inside the cavity (H-3, H-5), compared with the weak variations of the CD protons located outside $(\mathrm{H}-1, \mathrm{H}-2, \mathrm{H}-4)$. Upon complex formation, the large shielding of $\mathrm{H}-3$ and $\mathrm{H}-5$ reflects the presence of one of the RA aromatic rings in the CD cavity.

In Fig. S3, the ${ }^{1} \mathrm{H}$ NMR data of free and bound RA are compared. Maximal CD-induced deshielding occurs for aromatic protons.

The geometry of the RA-CD complex was further investigated via a ROESY experiment. Two different mixing times were used to obtain the NOE correlations between RA (350 ms) and CD $(150 \mathrm{~ms})$ (Fig. 4). As expected from the 1D NMR spectra, strong correlations were observed between the $\mathrm{CD} \mathrm{H}-3$ and $\mathrm{H}-5$ protons on the one hand and most of the RA protons on the other hand, especially $\mathrm{H}-2^{\prime}$ and $\mathrm{H}-5^{\prime}$ but also $\mathrm{H}-2$. No correlation was observed between the RA protons and the protons of the $\mathrm{CD}$ outer surface $(\mathrm{H}-2, \mathrm{H}-4)$. These results confirm without ambiguity the encapsulation of RA inside the CD cavity. The correlations between the $\mathrm{CD}$ protons and all RA aromatic protons suggest that both phenolic moieties can interact with the CD cavity. It can thus be assumed that two inclusion complexes are formed, one involving the caffeoyl moiety (complex 1, binding constant $K_{1}$ ) and the other one involving the 3.4-dihydroxyphenyllactic moiety (complex 2, binding constant $K_{2}$ ), both being in fast equilibrium via free RA. Overall, only a single averaged NMR spectrum is observed for the three species.

The observed chemical shift of any RA proton can be expressed as: $\delta_{\text {obs }}=x_{0} \delta_{0}+x_{1} \delta_{1}+x_{2} \delta_{2}, \delta_{0}, \delta_{1}$ and $\delta_{2}$ being the chemical shifts of the proton in free RA, complex 1 and complex 2, respectively, and $x_{0}, x_{1}$ and $x_{2}$ the corresponding mole fractions.

Simple solution chemistry gives:

$\delta_{o b s}=\frac{\delta_{0}+\left(\delta_{1} K_{1}+\delta_{2} K_{2}\right)[C D]}{1+\left(K_{1}+K_{2}\right)[C D]}=\frac{\delta_{0}+\delta_{\max } K_{b}[C D]}{1+K_{b}[C D]}$

With $K_{b}=K_{1}+K_{2}$ and $\delta_{\max }=\frac{\delta_{1} K_{1}+\delta_{2} K_{2}}{K_{1}+K_{2}}$

Therefore, whatever the proton signal detected, the apparent binding constant derived from the chemical shift variations is the same and equals the sum of the individual binding constants. It can thus be assumed that differences in $K_{\mathrm{b}}$ values depending on the RA proton detected merely reflect differences in sensivity.

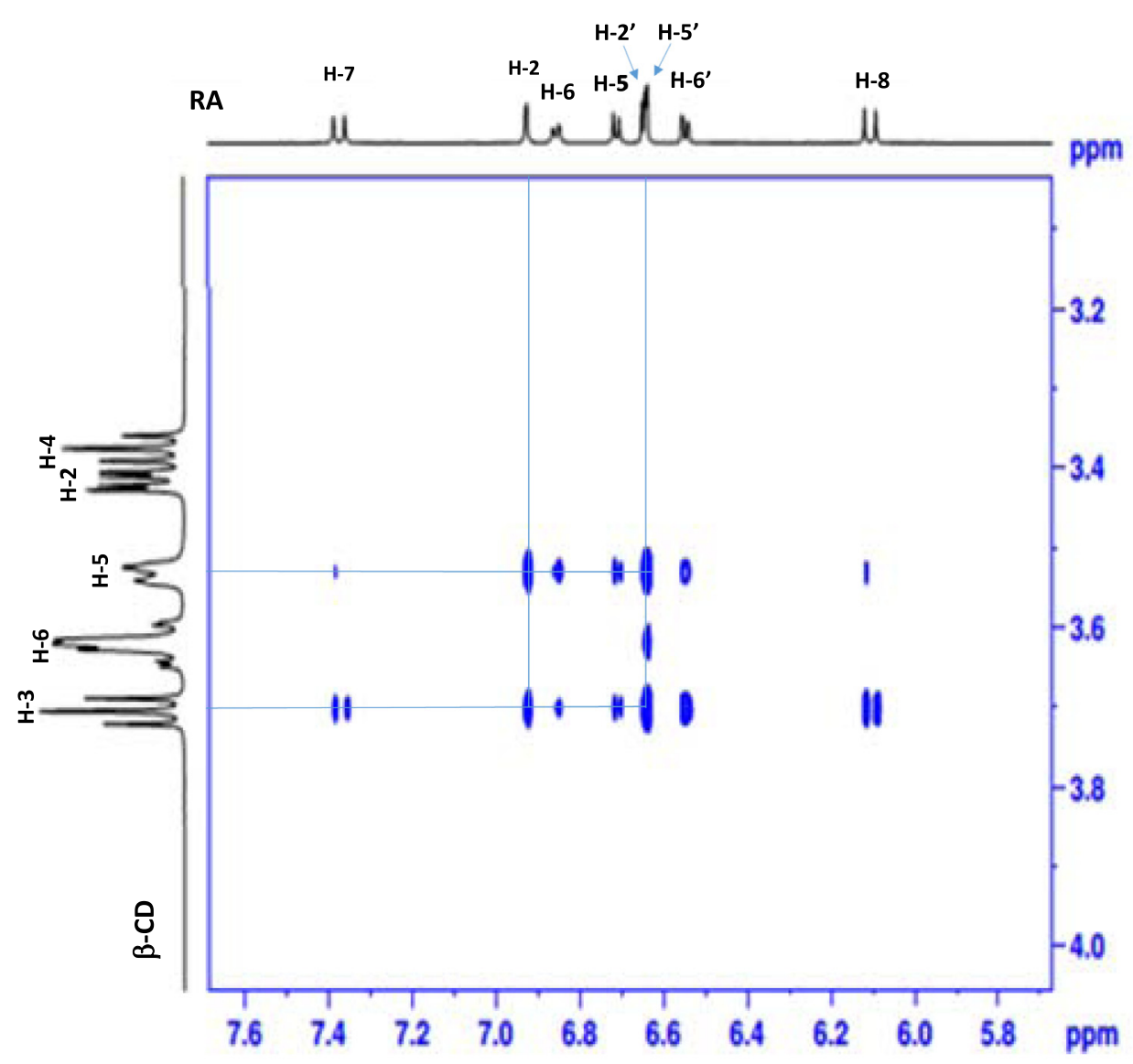

Fig. 4. ROESY spectrum of the $1: 1$ RA-CD complex ( $5 \mathrm{mM}$ of each partner) in $\mathrm{D}_{2} \mathrm{O}$ at $\mathrm{pH} 2.9$ (mixing time = $150 \mathrm{~ms}$ ). 
However, it can be noted that the NOE correlations are especially intense between with the $\mathrm{CD} \mathrm{H}-3$ and $\mathrm{H}-5$ protons and the vinylic protons of the caffeoyl part, which suggests a deep inclusion of this moiety into the cavity.

\section{4. $\mathrm{pH}$ dependence of binding}

The pH-dependence of the CD-RA complexation was investigated. At $\mathrm{pH}$ 2.9, $\mathrm{RA}$ is a mixture of neutral carboxylic $\left(\mathrm{RA}-\mathrm{CO}_{2} \mathrm{H}\right)$ and anionic carboxylate (RA- $\mathrm{CO}_{2}^{-}$) forms in nearly equal proportions. When the $\mathrm{pH}$ was decreased to 1 (pure $\mathrm{RA}-\mathrm{CO}_{2} \mathrm{H}$ ), the $K_{b}$ values deduced from Scott's plots for the RA protons (variable $C D$ concentration) were significantly higher. By contrast, when the $\mathrm{pH}$ was increased to 6 (pure RA-CO- ${ }_{2}^{-}$), the $K_{b}$ values were lower.

Clearly, the less hydrophilic carboxyl form display a higher affinity for the $\mathrm{CD}$ cavity than the corresponding carboxylate. On the other hand, at pH 1 and 6, the Job's plots confirmed the 1:1 stoichiometry of the inclusion complex (data not shown). As shown in Table 1 , the $K_{b}$ values obtained at pH 6 (ca. $200 \mathrm{M}^{-1}$ ) are of the same order of magnitude as those obtained by Celik et al. $\left(164 \mathrm{M}^{-1}\right)$ by fluorescence but much lower than those obtained by Medronho et al. by NMR. Indeed, at pH 6, Medronho et al. have estimated $K_{b}$ at ca. $1180 \mathrm{M}^{-1}$ and $2030 \mathrm{M}^{-1}$ depending on which RA aromatic ring is monitored and interpreted this difference by assuming two complexes in solution, the first one involving the caffeoyl moiety and the second the 3.4-dihydroxyphenyllactic moiety. As stated above, this interpretation is incorrect as both complexes are indistinguishable by NMR due to fast chemical exchange. Hence, differences in $K_{b}$ values must be ascribed to differences in sensitivity depending on the protons monitored and techniques adopted (detection on RA at variable CD concentration vs. detection on $\mathrm{CD}$ at variable RA concentration).

\subsection{Analysis of RA-CD inclusion complexes by capillary electrophoresis}

To confirm the NMR data, the RA-CD inclusion complex was also studied by CE. The electrophoretic mobility of RA was measured in buffered CD solutions at different concentrations (Li and Waldron, 1999). The binding kinetics being fast with respect to the separation time, the measured mobility $\mu$ is the average mobility of the free $\left(\mu_{R A}\right)$ and bound $\left(\mu_{R A-C D}\right)$ RA forms:

$\mu=(1-\alpha) \cdot \mu_{R A}+\alpha \cdot \mu_{R A-C D}$

$\alpha$ being the bound fraction of RA. For a large CD-to-RA molar ratio, the free $\mathrm{CD}$ concentration can be considered constant and equal to the total $C D$ concentration $C$, so that the binding constant can be expressed as:

Table 1

Maximal CD-induced ${ }^{1} \mathrm{H}$ NMR chemical shift displacements $\left(\Delta \delta_{\max }=\delta_{\max }-\delta_{0}\right.$ (no CD)) of RA protons and binding constant $\left(K_{\mathrm{b}}\right)$ at variable $\mathrm{pH}$ values in $\mathrm{D}_{2} \mathrm{O}$ ( $R A$ concentration $=1 \mathrm{mM}$ ).

\begin{tabular}{|c|c|c|c|c|c|c|}
\hline \multirow[b]{2}{*}{$\begin{array}{l}\text { RA } \\
\text { proton }\end{array}$} & \multicolumn{2}{|l|}{$\mathrm{pH} 1$} & \multicolumn{2}{|l|}{ pH 2.9} & \multicolumn{2}{|l|}{ pH 6} \\
\hline & $\begin{array}{l}\Delta \delta_{\max } \\
(\mathrm{ppm})\end{array}$ & $\begin{array}{l}K_{b} \\
\left(\mathrm{M}^{-1}\right)\end{array}$ & $\begin{array}{l}\Delta \delta_{\max } \\
(\mathrm{ppm})\end{array}$ & $\begin{array}{l}K_{b} \\
\left(\mathrm{M}^{-1}\right)\end{array}$ & $\begin{array}{l}\Delta \delta_{\text {max }} \\
(\mathrm{ppm})\end{array}$ & $\begin{array}{l}K_{b} \\
\left(\mathrm{M}^{-1}\right)\end{array}$ \\
\hline $\mathrm{H}-2$ & 0.08 & 320 & 0.01 & 265 & 0.14 & 209 \\
\hline $\mathrm{H}-2^{\prime}$ & 0.08 & 352 & 0.06 & 316 & 0.012 & 319 \\
\hline $\mathrm{H}-5$ & 0.09 & 314 & 0.02 & 260 & 0.4 & 256 \\
\hline $\mathrm{H}-5^{\prime}$ & 0.03 & 328 & 0.03 & 325 & 0.03 & 284 \\
\hline $\mathrm{H}-6$ & 0.07 & 300 & 0.09 & 260 & 0.13 & 202 \\
\hline H-6 $6^{\prime}$ & 0.09 & 330 & 0.06 & 328 & 0.02 & 238 \\
\hline $\mathrm{H}-7$ & 0.03 & 342 & 0.02 & 313 & 0.03 & 222 \\
\hline $\mathrm{H}-7^{\prime}$ & 0.05 & 468 & 0.03 & 390 & 0.04 & 230 \\
\hline $\mathrm{H}-8$ & 0.11 & 466 & 0.09 & 393 & 0.07 & 227 \\
\hline $\mathrm{H}-8^{\prime}$ & 0.11 & 466 & 0.08 & 299 & 0.07 & 227 \\
\hline
\end{tabular}

$K_{b}=\frac{[R A-C D]}{[R A][C D]}=\frac{\alpha}{(1-\alpha) \cdot C}$

Hence, the measured electrophoretic mobility can be expressed as a function of $C$ :

$\mu=\frac{\mu_{R A}+K_{b} C \cdot \mu_{R A-C D}}{1+K_{b} C}$

On top of binding effects, an increase in CD concentration leads to an increase in the buffer viscosity (Paduano, Sartorio, Vitagliano, \& Costantino, 1990), and this in turn influences all the electrophoretic mobilities, which are inversely proportional to the buffer viscosity (Plasson \& Cottet 2005). The electroosmotic flow $\mu_{\text {eof }}$ being inversely proportional to the buffer viscosity too (Corradini \& Sprecacenere, 2003), it was used for evaluating the viscosity correction factor to be applied to the measured electrophoretic mobilities (Li and Waldron, 1999). A linear relationship between the elution time of a neutral marker (phenol) $t_{\text {eof }}$ and the CD concentration was observed (correlation coefficient $R=0.92$ ). It corresponds to a linear variation of the viscosity with a maximal variation of $8 \%$ for a CD concentration of $15 \mathrm{mM}$.

The $K_{b}$ values can be obtained from the non-linear curve-fitting of the plot expressing the viscosity-corrected electrophoretic mobility $\mu$ as a function of $C$ according to Eq. (5), thus enabling the determination of the numerical values of $\mu_{R A}, \mu_{R A-C D}$ and $K_{b}$. The same method was repeated with caffeic acid (CA) for comparison purposes, as CA is structurally related to RA (see Fig. 1). The measurements were performed at $20^{\circ} \mathrm{C}$. The $\mathrm{pH}$ was fixed at 7 so as to ensure that the carboxyl groups of RA and CA are fully deprotonated. The ionic strength was fixed to a low value of $10 \mathrm{mM}$ in order to avoid any heating of the capillary. Moreover, in those conditions, the ionic and actual electrophoretic mobilities can be taken equal (Plasson \& Cottet, 2005).

The non-linear curve fitting yields: $K_{b}=197 \quad( \pm 14) \mathrm{M}^{-1}$, $\mu_{R A}=1.520 \quad( \pm 0.006) \times 10^{-8} \mathrm{~m}^{2} \mathrm{~V}^{-1} \mathrm{~s}^{-1}$ and $\mu_{R A-C D}=0.934$ $( \pm 0.014) \times 10^{-8} \mathrm{~m}^{2} \mathrm{~V}^{-1} \mathrm{~s}^{-1}$ for $\mathrm{RA}, K_{b}=176( \pm 4) \mathrm{M}^{-1}, \mu_{C A}=2.101$ $( \pm 0.003) \times 10^{-8} \mathrm{~m}^{2} \mathrm{~V}^{-1} \mathrm{~s}^{-1}$ and $\mu_{C A-C D}=1.047 \quad( \pm 0.014) \times 10^{-8}$ $\mathrm{m}^{2} \mathrm{~V}^{-1} \mathrm{~s}^{-1}$ for CA (see Fig. 5).

The similar $K_{\mathrm{b}}$ values for RA and CA suggest that the caffeoyl moiety of RA is mostly responsible for the affinity of RA for CD and that the less polarizable dihydroxyphenyllactic moiety experiences a weaker binding. Taking hydroxytyrosol as a structural analog of the dihydroxyphenyllactic moiety, it can actually be noted that this olive phenol only weakly binds $C D$ with a $K_{\mathrm{b}}$ value of ca. $90 \mathrm{M}^{-1}$ (López-García et al., 2010).

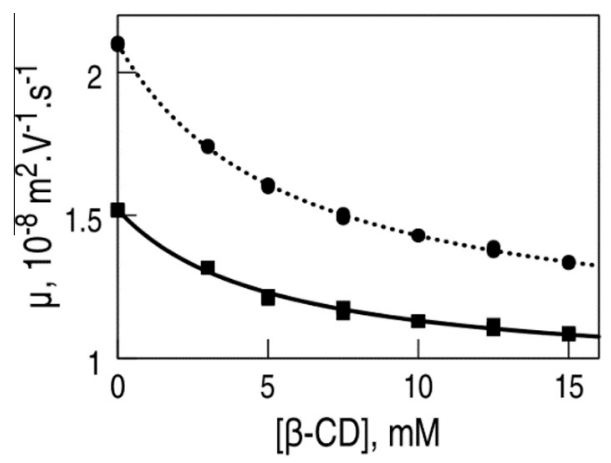

Fig. 5. Variation of the electrophoretic mobility of RA (solid line and squares) and $\mathrm{CA}$ (dotted line and circles) as a function of the total CD concentration, in phosphate buffer at $\mathrm{pH} 7,20^{\circ} \mathrm{C}, \mathrm{I}=10 \mathrm{mM},[\mathrm{RA}]=0.05 \mathrm{mM},[\mathrm{CA}]=0.2 \mathrm{mM}$. Circles and squares are experimental measurements for respectively $C A-C D$ and $R A-C D$, each of them being repeated three times. The lines were obtained by non-linear curve-fitting of experimental data using Eq. (5). 
The electrophoretic mobilities can also be used to evaluate the hydrodynamic radius of each species (Plasson \& Cottet, 2005):

$$
r_{i}=\frac{q}{6 \pi \eta \mu_{i}}
$$

with $q$ the electric charge of the compounds $\left(1.6 \times 10^{-19} \mathrm{C}\right)$ and $\eta$ the water viscosity at $20^{\circ} \mathrm{C}\left(10^{-3}\right.$ Pa.s $)$. This gives $r \mathrm{RA}=5.6 \AA$, $r_{\mathrm{CA}}=4.0 \AA, r \mathrm{RA}_{-\mathrm{CD}}=9.1 \AA, r_{\mathrm{CA}-\mathrm{CD}}=8.1 \AA$. These values can be compared with the hydrodynamic value of $\beta-C D: r_{C D}=7.7 \AA$ (Pavlov, Korneeva, Smolina, \& Schubert 2010). They are consistent with the inclusion of either RA or CA inside the $\beta-C D$ cavity, as evidenced by a slight radius increase from free $\beta-C D$ to the $C A-\beta-C D$ and $R A-\beta-$ CD complexes.

Close $K_{b}$ values are thus obtained for RA- $\beta-C D$ with this method and with the NMR method in neutral conditions (about $200 \mathrm{M}^{-1}$, see Table 1 ) with a similar precision (about $10 \%$ error).

This value is also in good agreement with the one determined by Celik et al. by fluorescence $\left(164 \pm 65 \mathrm{M}^{-1}\right)$ rather than with the value obtained by NMR by Medrohno et al. (ca. $2000 \mathrm{M}^{-1}$ ). The consistency of EC methods with fluorescence methods was furthermore checked by performing a similar study for the association of RA with methyl- $\beta-C D$. A $K_{b}$ value of $372( \pm 20) \mathrm{M}^{-1}$ was determined; once again, this value is in perfect agreement with the value measured by Celik et al. $\left(328 \pm 39 \mathrm{M}^{-1}\right)$.

\section{Conclusion}

The complementary use of $1 \mathrm{D}$ and 2D ROESY NMR and EC methods have led to consistent results concerning the complex formation between RA and $\beta$-CD. In all conditions, a mixture of $1: 1$ complexes in fast equilibrium was obtained, both catechol subunits of RA being potentially inserted inside the $C D$ hydrophobic cavity, while no interactions of RA with the outside of the CD unit could be reliably detected. Typically, the apparent binding constant is ca. $450 \mathrm{M}^{-1}$ at pH 2.9 (equimolar mixture of the carboxyl and carboxylate forms), corresponding to an encapsulation efficiency of ca. $50 \%$ when the two species are mixed in an equimolar concentration of $5 \mathrm{mM}$ each. The $\mathrm{pH}$ dependence of $K_{b}$ shows that the carboxyl form of RA displays a higher affinity for the macrocycle than the carboxylate form.

In conclusion, RA forms a relatively stable complex with $\beta-C D$, especially in acidic conditions. By accommodating the catechol nuclei inside the CD cavity, the binding could inhibit their interactions with redox-active metal traces, thereby providing higher stability for food applications. The binding could also modulate the release of RA in the digestive tract as a function of $\mathrm{pH}$.

\section{Acknowledgements}

The authors thank Roquette Freres (Lestrem, France) for providing $\beta$-cyclodextrin.

\section{Appendix A. Supplementary data}

Supplementary data associated with this article can be found, in the online version, at http://dx.doi.org/10.1016/j.foodchem.2016. 04.008.

\section{References}

Ali, S. M., \& Upadhyay, S. K. (2008). Complexation studies of pioglitazone hydrochloride and $\beta$-cyclodextrin: NMR ( $\left.{ }^{1} \mathrm{H}, \mathrm{ROESY}\right)$ spectroscopic study in solution. Journal of Inclusion Phenomena and Macrocyclic Chemistry, 62, 161-165.

Astray, G., Gonzalez-Barreiro, C., Mejuto, J. C., Rial-Otero, R., \& Simal-Gándara, J. (2009). A review on the use of cyclodextrins in foods. Food Hydrocolloids, 23, 1631-1640.

Çelik, S. E., Özyürek, M., Tufan, A. N., Güçlü, K., \& Apak, R. (2011). Spectroscopic study and antioxidant properties of the inclusion complexes of rosmarinic acid with natural and derivative cyclodextrins. Spectrochimca Acta A Molecular Biomolecular Spectroscopy, 78, 1615-1624.

Corradini, D., \& Sprecacenere, L. (2003). Dependence of the electroosmotic flow in bare fused-silica capillaries from $\mathrm{pH}$, ionic strength and composition of electrolyte solutions tailored for protein capillary zone electrophoresis. Chromatographia, 58, 587-596.

Cravotto, G., Binello, A., Baranelli, E., Carraro, P., \& Trotta, F. (2006). Cyclodextrins as food additives and in food processing. Current Nutrition and Food Science, 2, $343-350$.

Fang, Z., \& Bhandari, B. (2010). Encapsulation of polyphenols. Trends in Food Science E' Technology, 21, 510-523.

Furtado, M. A., de Almeida, L. C. F., Furtado, R. A., Cunha, W. R., \& Tavares, D. C. (2008). Antimutagenicity of rosmarinic acid in Swiss mice evaluated by the micronucleus assay. Mutation Research, 657, 150-154.

Koontz, J. L., Marcy, J. E., O’Keefe, S. F., \& Duncan, S. E. (2009). Cyclodextrin inclusion complex formation and solid-state characterization of the natural antioxidants $\alpha$-tocopherol and quercetin. Journal of Agriculture and Food Chemistry, 57, 1162-1171.

Lecomte, J., Giraldo López, L. J., Laguerre, M., Baréa, B., \& Villeneuve, P. (2010). Synthesis, characterisation and free radical scavening properties of rosmarinic acid fatty esters. Journal of the American Oil Chemists Society, 87, 615-620.

Li, J., \& Waldron, K. C. (1999). Estimation of the pH-independent binding constants of alanylphenylalanine and leucylphenylalanine stereoisomers with $\beta$ cyclodextrin in the presence of urea. Electrophoresis, 20, 171-179.

Li, J., Zhang, M., Chao, J., \& Shuang, S. (2009). Preparation and characterization of the inclusion complex of Baicalin (BG) with $\beta-C D$ and $H P-\beta-C D$ in solution: An antioxidant ability study. Spectrochimica Acta Part A, 73, 789-793.

Loftsson, T., Jarho, P., Másson, M., \& Järvinen, T. (2005). Cyclodextrins in drug delivery. Expert Opinion on Drug Delivery, 2, 335-351.

López-García, M. Á., López, Ó., Maya, I., \& Fernández-Bolaños, J. G. (2010). Complexation of hydroxytyrosol with $\beta$-cyclodextrins. An efficient photoprotection. Tetrahedron, 66, 8006-8011.

Medronho, B., Valente, A. J. M., Costa, P., \& Romano, A. (2014). Inclusion complexes of rosmarinic acid and cyclodextrins stoichiometry, association constants, and antioxidant potential. Colloid and Polymer Science, 292, 885-894.

Munin, A., \& Edwards-Lévy, F. (2011). Encapsulation of natural polyphenolic compounds. Pharmaceutics, 3, 793-829.

Mura, P. (2014). Analytical techniques for characterization of cyclodextrin complexes in aqueous solution. Journal of Pharmaceutical and Biomedical Analysis, 101, 238-250.

Paduano, L., Sartorio, R., Vitagliano, V., \& Costantino, L. (1990). Diffusion properties of cyclodextrins in aqueous solution at $25^{\circ} \mathrm{C}$. Journal of Solution Chemistry, 19, 31-39.

Pavlov, G. M., Korneeva, E. V., Smolina, N. A., \& Schubert, U. S. (2010). Hydrodynamic properties of cyclodextrin molecules in dilute solutions. European Biophysics Journal, 39, 371-379.

Pessine, F. B., Calderini, A., \& Alexandrino, G. L. (2012). a review: Cyclodextrin inclusion complexes probed by NMR techniques. In D. H. Kim (Ed.), Magnetic resonance spectroscopy. InTech Publishing.

Petersen, M., \& Simmonds, M. S. (2003). Rosmarinic acid. Phytochemistry, 62, $121-125$.

Plasson, R., \& Cottet, H. (2005). Determination of homopolypeptide conformational changes by the modeling of electrophoretic mobilities. Analytical Chemistry, 77. 6047-6054.

Campos-Vega, Rocio., Guadalupe Loarca-Piña, B., \& Oomah, Dave. (2010). Minor components of pulses and their potential impact on human health. Food Research International, 43, 461-482.

Schneider, H., Hacket, F., \& Rudiger, V. (1998). NMR studies of cyclodextrins and cyclodextrin complexes. Chemical Reviews, 98, 1755-1785.

Szejtli, J. (1998). Introduction and general overview of cyclodextrin chemistry. Chemical Reviews, 98, 1743-1753.

Szente, L., \& Szejtli, J. (2004). Cyclodextrins as food ingredients. Trends in Food Science \& Technology, 15, 137-142.

Wang, Y., Qiao, X., Li, W., Zhou, Y., Jiao, Y., Yang, C., Dong, C., et al. (2009). Study on the complexation of isoquercitrin with $\beta$-cyclodextrin and its derivatives by spectroscopy. Analytica Chimica Acta, 650, 118-123.

Zhang, M., Li, J., Zhang, L., \& Chao, J. (2009). Preparation and spectral investigation of inclusion complex of caffeic acid with hydroxypropyl- $\beta$-cyclodextrin. Spectrochimica Acta Part A, 71, 1891-1895. 